\title{
ICTV Virus Taxonomy Profile: Finnlakeviridae
}

\section{Mäntynen, Sari Susanna}

2020

Mäntynen , S S , Laanto , E , Sundberg , L-R , Poranen, M , Oksanen , H M \& ICTV Report Consortium 2020 , ' ICTV Virus Taxonomy Profile: Finnlakeviridae ' , Journal of General Virology , vol. 101 , no. 9 , pp. 894-895 . https://doi.org/10.1099/jgv.0.001488

http://hdl.handle.net/10138/320459

https://doi.org/10.1099/jgv.0.001488

cc_by

publishedVersion

Downloaded from Helda, University of Helsinki institutional repository.

This is an electronic reprint of the original article.

This reprint may differ from the original in pagination and typographic detail.

Please cite the original version. 


\title{
ICTV Virus Taxonomy Profile: Finnlakeviridae
}

\author{
Sari Mäntynen ${ }^{1,2}+$, Elina Laanto ${ }^{1,3}$, Lotta-Riina Sundberg ${ }^{3}$, Minna M. Poranen ${ }^{1}$, Hanna M. Oksanen ${ }^{1, *}$ and ICTV Report \\ Consortium
}

\begin{abstract}
Finnlakeviridae is a family of icosahedral, internal membrane-containing bacterial viruses with circular, single-stranded DNA genomes. The family includes the genus, Finnlakevirus, with the species, Flavobacterium virus FLiP. Flavobacterium phage FLiP was isolated with its Gram-negative host bacterium from a boreal freshwater habitat in Central Finland in 2010. It is the first described single-stranded DNA virus with an internal membrane and shares minimal sequence similarity with other known viruses. The virion organization (pseudo $T=21$ dextro) and major capsid protein fold (double- $\beta$-barrel) resemble those of Pseudoalteromonas phage PM2 (family Corticoviridae), which has a double-stranded DNA genome. A similar major capsid protein fold is also found in other double-stranded DNA viruses in the kingdom Bamfordvirae. This is a summary of the International Committee on Taxonomy of Viruses (ICTV) report on the family Finnlakeviridae, which is available at ictv.global/report/ finnlakeviridae.
\end{abstract}

Table 1. Characteristics of members of the family Finnlakeviridae

\begin{tabular}{|ll|}
\hline Typical member: & Flavobacterium phage FLiP (MF361639), species Flavobacterium virus FLiP, genus Finnlakevirus \\
\hline Virion & Icosahedral, internal membrane-containing virions, approximately $59 \mathrm{~nm}$ in diameter. Spikes protrude from the virion surface \\
Genome & $9.2 \mathrm{~kb}$ of circular, single-stranded DNA \\
Replication & Possibly rolling circle replication \\
Translation & By the host translation machinery \\
Host range & Gram-negative bacteria from the genus Flavobacterium \\
Taxonomy & The genus Finnlakevirus includes the species Flavobacterium virus FLiP \\
\hline
\end{tabular}

\section{VIRION}

The virion of Flavobacterium phage FLiP consists of an icosahedral protein shell and an internal membrane, uniquely combined with a circular ssDNA genome [1] (Table 1, Fig. 1). The diameter of the virion is about $59 \mathrm{~nm}$ (vertex-to-vertex). Pentameric spike complexes protrude about $12 \mathrm{~nm}$ from the protein shell surface at the fivefold vertices. The inner surface of the icosahedral protein capsid is covered by a lipid bilayer membrane ( $5 \mathrm{~nm}$ thick), enclosing the single-stranded DNA genome. The major capsid proteins (MCPs) forming the outer protein shell follow a pseudo $T=21$ dextro icosahedral capsid organization, previously described only for the marine doublestranded DNA Pseudoalteromonas phage PM2 [2]. The Flavobacterium phage FLiP MCPs consist of two $\beta$-barrels with jellyroll topology and arrange into trimers to form pseudohexameric molecules [1]. A similar major capsid protein fold has also been described for members of the kingdom Bamfordvirae [3], such as Enterobacteria phage PRD1 (family Tectiviridae) [4].

Received 28 July 2020; Accepted 05 August 2020; Published 25 August 2020

Author affiliations: ${ }^{1}$ Molecular and Integrative Biosciences Research Programme, Faculty of Biological and Environmental Sciences, University of Helsinki, Viikinkaari 9, 00014 University of Helsinki, Finland; ${ }^{2}$ Department of Microbiology and Molecular Genetics, University of California, Davis, One Shields Avenue, Davis, California 95616, USA; ${ }^{3}$ Department of Biological and Environmental Science and Nanoscience Center, University of Jyväskylä, Survontie 9, 40014 University of Jyväskylä, Finland.

*Correspondence: Hanna M. Oksanen, hanna.oksanen@helsinki.fi

Keywords: ICTV report; taxonomy; Finnlakeviridae; Flavobacterium phage FLiP; icosahedral membrane-containing virus; single-stranded DNA phage. Abbreviations: CDS, coding sequence; MCP, major capsid protein; $T$, triangulation number.

†These authors contributed equally to this work

001488 (c) 2020

(c) (1) This is an open-access article distributed under the terms of the Creative Commons Attribution License. 

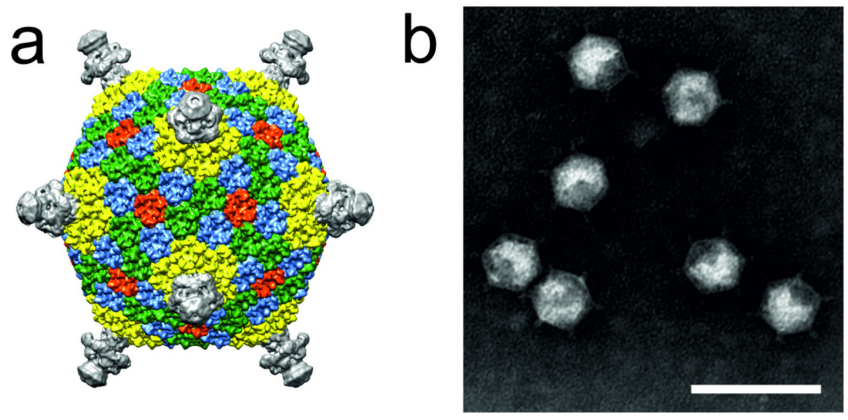

Fig. 1. Flavobacterium phage FLiP virion structure. (a) Cryo-electron microscopic reconstruction [1]. (b) virions negatively-stained with $2 \%$ phosphotungstic acid $(\mathrm{pH} 8.5)$ and visualized under transmission electron microscopy. Scale bar represents $100 \mathrm{~nm}$.

\section{GENOME}

Virions contain a single copy of a circular single-stranded DNA of 9174 nucleotides with a GC content of 34\% [1]. 16 predicted coding sequences (CDS), all in the same orientation (Fig. 2), show limited similarity with other known sequences. Five CDSs have been shown to encode structural proteins (CDS7-9, 11, 14). There are sequence similarities between CDS14 and several lytic transglycosylases and between CDS15 and rolling circle replication proteins $[1,5]$.

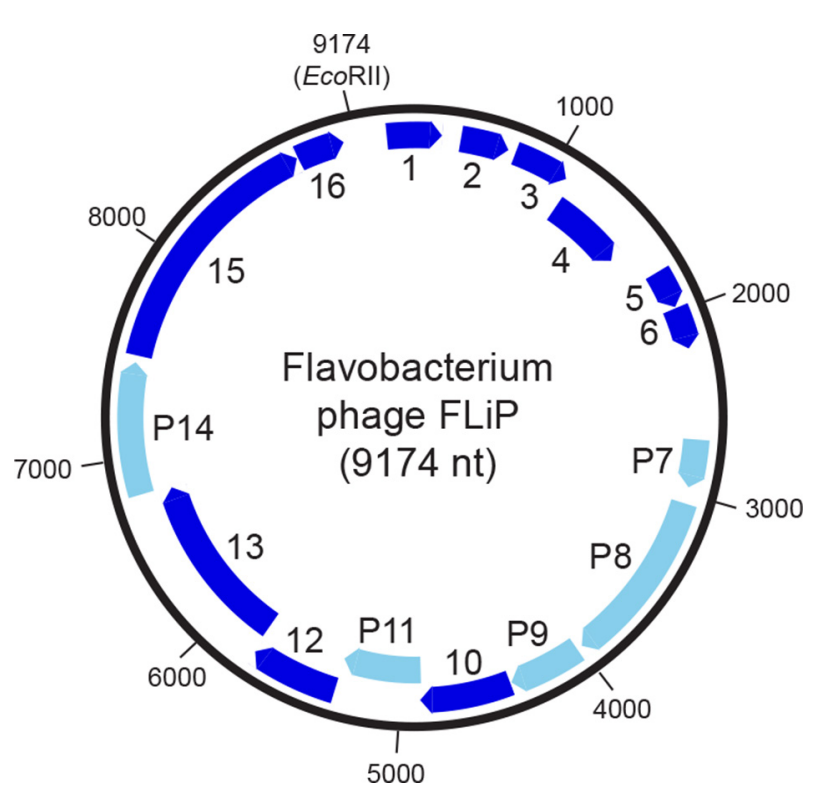

Fig. 2. Genome organization of Flavobacterium phage FLiP. Arrows show the direction of transcription of predicted CDSs, with light blue indicating those encoding the structural proteins P7-9, P11 and P14. The unique EcoRII restriction site is at nucleotide position 1.

\section{REPLICATION}

Flavobacterium phage FLiP is a virulent virus that induces host-cell lysis at the end of the viral reproduction cycle [1]. CDS14 is predicted to encode a virion-associated lytic protein likely assisting in the penetration of the host peptidoglycan layer during entry. Flavobacterium phage FLiP does not encode any identifiable DNA or RNA polymerase. However, the sequence resemblance of CDS15 to rolling circle replication proteins suggests a replication mechanism typical of single-stranded DNA viruses $[1,5]$. The absence of a putative packaging ATPase implies that a viral-encoded ATPase is not required for the encapsidation of the genome [5].

\section{TAXONOMY}

Current taxonomy: ictv.global/report/finnlakeviridae. The family Finnlakeviridae contains the genus Finnlakevirus with the species Flavobacterium virus FLiP. Based on phylogenetic analysis of MCP sequences, Flavobacterium phage FLiP forms its own group among the tailless prokaryotic DNA viruses and proviruses with double- $\beta$-barrel MCPs [5].

\section{RESOURCES}

Current ICTV Report on the family Finnlakeviridae: ictv. global/report/finnlakeviridae

Funding information

This work was supported by the Academy of Finland grants \#323426 (S.M.), \#321985 (E.L.) and \#314939 (L.-R.S.), Jane and Aatos Erkko Foundation (L.-R.S. nd M.M.P.) and Sigrid Jusélius Foundation (M.M.P). H.M.O was supported by the University of Helsinki and Academy of Finland funding for FINStruct and Instruct CentreFI, part of Biocenter Finland and Instruct-ERIC. Production of this summary, the online chapter and associated resources was funded by a grant from the Wellcome Trust (WT108418AIA).

\section{Acknowledgements}

Members of the ICTV Report Consortium are Stuart G. Siddell, Andrew J. Davison, Elliot J. Lefkowitz, Peter Simmonds, Sead Sabanadzovic, Donald B. Smith, Richard J. Orton and Evelien Adriaenssens.

\section{Conflicts of interest}

The authors declare that there are no conflicts of interest.

\section{References}

1. Laanto E, Mäntynen S, De Colibus L, Marjakangas J, Gillum A et al. Virus found in a boreal lake links ssDNA and dsDNA viruses. Proc Natl Acad Sci USA 2017;114:8378-8383.

2. Huiskonen JT, Kivelä HM, Bamford DH, Butcher SJ. The PM2 virion has a novel organization with an internal membrane and pentameric receptor binding spikes. Nat Struct Mol Biol 2004;11:850-856.

3. Koonin EV, Dolja VV, Krupovic M, Varsani A, Wolf YI et al. Global organization and proposed megataxonomy of the virus world. Microbiol Mol Biol Rev 2020;84

4. Benson SD, Bamford JK, Bamford DH, Burnett RM. Viral evolution revealed by bacteriophage PRD1 and human adenovirus coat protein structures. Cell 1999:98:825-833.

5. Yutin N, Bäckström D, Ettema TJG, Krupovic M, Koonin EV. Vast diversity of prokaryotic virus genomes encoding double jelly-roll major capsid proteins uncovered by genomic and metagenomic sequence analysis. Virol J 2018;15:67. 